\title{
Creative Thinking: One Step Ahead for Technical Aspirants and Business Professionals
}

\author{
Ajaya Kumar Moharana, \\ ${ }^{1}$ (English, Orissa Engineering College, Bjiupatnaik University of Technology, Odisha, India
}

\begin{abstract}
Creativity is à special skill that works wonder by designing the approach towards a problem in a different way. We often confront bottlenecks and get confused. Here lateral thinking only stimulates to get ideas. Once new ideas pour in, it gets merged with another one and subsequently this combination generates a truly original idea. This paper envisages at improvising the creative approach of the business professionals as well as technical aspirants willing to get rid of stress, stumbling blocks and problem related to their workplace. Further, the detailed analysis of problems and techniques will arouse their inherent creativity to combat day to day problems. Once they get hold of this technique, creativity will be spontaneous; they will never stop trying this lateral technique. It is further exemplified with details to persuade a person for creative technique that proves itself the ultimate solution in it.
\end{abstract}

Keywords - Analysis, Business Professionals, Creativity, technical aspirants, workplace

\section{Introduction}

In our society the headaches of a lot of corporate leaders and budding technical students are to set themselves well in the faster changing world. Success and failure are like two parts of a coin play pranks with them. In a state of flux they neither get extreme pleasure nor remain silent trying more. The situation becomes so embarrassing that they even react negatively as vindicated in their body language.

Thus, business organizations and academic institutions need to develop a situation where all such obstacles seem vanishing and the footprints of solution become prominent. When we discuss such themes creative thinking is one the ideas stimulates everybody. Therefore, the institutions and organizations should come up with a creative syllabus where a special slot may be kept for practical learning on lateral thinking skills. Jodiac Webster hinted at it in 1997 describing two types of school: Ready for change and not ready for change. The first one already taken creative approach by collaborating with local industry to form closer ties, and preparing students to work in those companies and second one was happy with its comfortable zone, employing their students in faculty positions and did not seem to go for any changes.

It is though popular in New Zealand, USA, UK, it also needs to be popularized in Indian based institutions and organizations. Teachers should encourage their students to promote their creative skill and refrain from drugs and alcohols. A student friendly platform should be there for open ended interactions. As a guide, philosopher and friend teachers may control them even being humorous in their tone. Teach them the following: [1] In Case of Emergency (P 23, Foster)

- Grab your coat

- Get your hat

- Leave your worries on the door step

- Direct your feet to the sunny side of the street

Applying different tools in the workplace, let students and employees understand the challenge and think out of box for a better solution.

\section{Objective:}

The objective here gives an insight to following:

1. Techniques and procedure will enable the students and corporate leaders to combat day to day problems.

2. Compel them to think out of box.

3. Practice thinking as a skill not as a compulsion.

4. Are they prepared for a change?

This article briefs some of the aspects of lateral thinking and the justification of its application in professional as well as educational life. 


\section{III.1 Our Parents}

\section{Our Problems:}

The so called Daddies and Mommies are over ambitious. They are possessive about the career of their children. Being ignorant of their children's inherent interest, they go on mounting academic pressure; as a result they either turn out violent or insane ones.

\section{III.2 Business Managers}

Highly ambitious managers ensure their staff to make miracles always. It becomes difficult to retain staff. The failure to identify their particular skill mars professionalism among them and consequently they become jack of all trade and master of none.

\section{III.3 Practice in Educational Institute}

It is observed that if students do not write the dictated answers in the class tests, they are sure of getting miserable marks. We simply hinder the inherent talent to come up. Numero Uno is not the solution, but how practical and intelligible they are in their workplace is the question.

\section{III.4 Attempting Questions}

A lot of students prepare for competitive examinations in a traditional way (browsing over previous year's questions). But very few think out of box. They approach towards questions in a different way.

The problem lies not only in our working culture, but in our thinking system. De Bono has rightly observed it and appealed to go for a creative thinking. We have a problem in perceiving a problem. [2] De Bono has rightly said, "All criminals are seen first as criminal” ( $\mathrm{P} 43$, de Bono)

Problem factor controls the central idea of the paper. Why should one have problem? If a problem occurs, how do we face it? These are few aspects of our ordinary life. Look at the possible reasons behind:

\section{III.5 Our Faults}

III.5.1

Education: The common practice is basically listening, comprehending, thinking and analyzing in educational sectors. There are two types of thinking-critical and creative. [3] "Pre-eminence of critical thinking is considered the highest form of civilized thinking and the defense of civilization itself" (P 06, de Bono). We are, however, strong in critical thinking but lack in creative. As rightly said by de Bono, [4] "Critical thinking lacks the productive, generative, creative and design elements" (P 06, de Bono). We stop the creative skill to come up as we are in a world of self contentment. We do not look at alternatives and want to be active. Things go on as it is.

No doubt, we get prestigious degrees, but we end up with lesser ability to think creatively though we are adept in logical and critical thinking. Once in a Seminar in Aug-2012 on "Better Graduates for a better tomorrow" held at May Fair Lagoon, Bhubaneswar by Pearson publications pvt. ltd, educationists from reputed universities like Ravenshaw, Cuttack and Utkal, Bhubaneswar put forth their point of view on recruiting highly experienced and trained teachers but stumbled over a question that whether they could put pressure on the department of education to induct a separate subject on "Thinking as a Skill" in the graduation syllabus. The Vice Chancellor of Ravenshaw University only assured of doing so but left everything to the panel of subject specialists and the government. If we barely need a change, the mind set has to be changed, someone has to think and take risk. Once Edward De Bono said during the time of a personal interview with Shekhar Gupta, chief editor of The Indian Express, 2008 [5] that if girls put a condition to marry people who were able to think, people would start thinking (Int. with de Bono, by Shekhar Gupta). Another disease of our so called educated people is to suppress the hidden talent of poor students by saying, "You're good for nothing" or "Are you crazy? If such temperament remains they cannot be good thinkers.

\section{III.5.2}

Social Sectors- Our society has never done justice to the poor to voice in the crowd. Their voice is suppressed. Even they express a noble idea; it is rejected as null and void. He either draws him back or remains silent.

Since traditional or vertical processes are rampant in nature, it is too difficult to change the mindset of the people. We learn to annihilate such dogma in our society.

III.5.3

Political Sectors- In politics even the most eligible candidate gets stumbled. Instead of acknowledging the right choice, the nasty political leaders get rid of them by their muscular and financial strength. 
The situation has become so worst that an educated and sincere person feels reluctant to enter into this world of hypocrisy where human value is soiled. A creative person is threatened to life. Problem is not that somebody is losing the game, but his life is at stake and welcoming a ruffian to rule.

\section{Lateral Thinking Skills:}

[6] "More than any other time in the history, mankind faces a crossroads. One path leads to despair and utter hopelessness, the other to total extinction. Let us pray we have the wisdom to choose correctly."

-Woody Allen- (P 01, Foster)

Our major concern is to go ahead. But going ahead in the same direction is not our chief aim. Most of the students and business personnel don't spend time to look for a better model; they follow the same orthodox track. A Management Guru Gary Hamel says, [7] "Most companies are built for continuous improvement, rather than for continuous innovation. They know how to get better, but they don't know how to get different." (P 5, Sloane)

Creativity is an inherent talent that lies in us, but very few of us recognize it; those who recognize its presence, they start working differently. Successful business leaders do not allow success to blunt the way for innovation. One has to remember that just doing better is the not enough. Creativity is not an end in itself; it is a means to an end. Paul Sloane has rightly said, [8] "The difference between creative thinking and lateral thinking is the difference between introducing any kind of new shop and introducing a new approach to shopping entirely-the supermarket" (P 08, Sloane). In Stephen Covey's book, [9] The Seven Habits of Highly Effective People (1989), he says that most people focus on what is urgent (whether it is important or not), but successful people focus also on what is important but not urgent (P 29 Sloane).

IV.1 Use the following \& spark our creativity:

IV.1.1 Pattern Making System

As we use our mind in thinking, we must aware of the 'pattern making system'. Thus, the nature of the movement of information determines what sort of structure will be formed from a pattern whether a demon or sage.

\section{Vertical thinking}

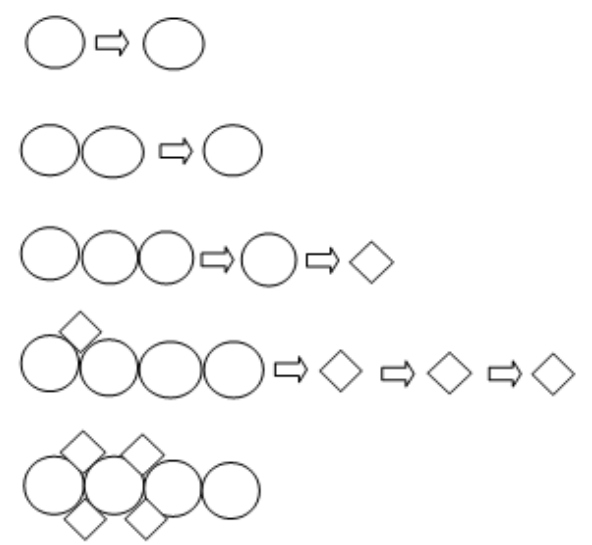

\section{Lateral thinking}

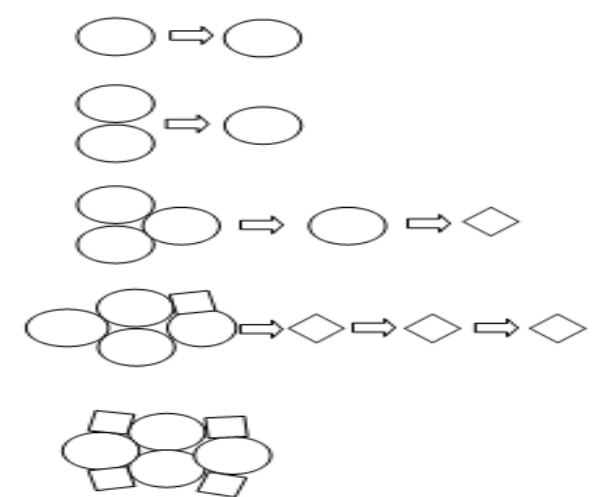

Fig. 1 


\section{IV.1.2 Think beyond the limit}

Thinking within the limit is like [10] "Everything that can be invented has been invented" (P 1, Campbell, http://www.refresher.com/!slcbox.html, Policies...Keeping Us Thinking Inside the Box, 2004) said Charls H.Duell, Director of the US Patent Office. Look at the following:

- Being asked by Ford Motor Corporation "How can we make our cars more attractive for the customers?" De Bono simply suggested buying up car parking areas in the city.

- Jack Foster while working in an advertizing company (in the creative department), being asked by [11] Los Angeles Times how to fix the dressing of the employees, suggested that even they could come with their pajamas. Making a fun, workers got homely and made those days highly productive.(P 24, Foster)

- Once upon a time a man painted half of his car white and another half black. On being asked the reason behind it, he replied, [12] "Because it is such fun, whenever I have an accident, to hear the witness in court contradict each other" (P 2, de Bono).

- A major French construction company asked every new employee to complete an [13] 'astonishment report' after they have been in the company for a few weeks'.(P 43, Sloane)

- Once Colgate private limited held a meeting with its marketing executives to discuss how to increase sales of toothpaste. One of the executives opined whether it was possible to widen the mouth of the toothpaste, so that the customer would get more than actually required.

- In 1968, at the Olympics Games in Mexico City saw a young man making high jump using his feet to the bar. This idea prompted a young American, Dick Fosbury, who came up with the idea to make it using the back to the bar.

- Kerry Packer introduced day/night matches and colourful ball and clothing in cricket. In the same breath Australia recently experimented with two different captains for Test and ODIs (One Day Internationals).

- Ensuring people's participation through attractive captions in media. For example on Odisha TV: YOU ARE NOT ALONE, WE REPORT YOU DECIDE. Once these clicked, followed immediately by others.

\section{IV.1.3 Bring Sense of Humour}

Sense of humour creates win-win situation. Look at the following:

- At a dinner one day Mr. Churchill sat down nest to Lady Astor. She turned to him and said, [14] "Mr. Churchill, if I was married to you I should put poison in your coffee". Mr. Churchill turned to her said, “ Madam, if I was married to you ...I should drink the coffee"(P 34, de Bono)

- Two friends (one at 80 and another 85) named Mohit and Rakesh were having their time nicely after retirement. One day Rakesh passed away and after a few days Mohit. In the hell Mohit saw that Rakesh was having fun with a young beautiful girl aged around 16 sitting on his thigh and kissing him. To this Mohit shouted, "It's not punishment! It's not hell! You're having fun!" Rakesh said, "Listen my dear, it's the punishment for the girl".

\section{IV.1.4 Do something New}

In mobile network BSNL cracked first and then followed by RIM, Airtel, Hutch (Now Vodafone), Aircel, Tata Indicom and S Tel. But what was new in them? They made it handier with unlimited offer, tariff, and hassle free network. They sustained in the market not because of newness but by approaching the limitations in a different way.

Conduct the meeting in the garden, annual family day celebration, art and craft competition among the children, reward excellent works, recognize talents and give opportunities, take RISK, stop blaming others, be pro active not retroactive.

\section{IV.1.5 Do SMART work}

We are aware of HARD and SMART work. Of course books are available to generate ideas. But doing hard work is not the same with smart work. One has to be creative and smart. Let me tell a story:

Once the proprietor of a Bungalow called two of his gardeners and gave them a responsibility to shape the total garden in 7 days (50\% each). One was able to complete within 7 days and other within 4 . The later was awarded as did the smart work by sharpening the blade of knife every morning. The former did hard work, but with the blunt knife, and therefore no reward.

\section{IV.1.6 Reversal Methods}

- The teacher teaches the students

- The students disrupt it 
Which of these methods seems a better proposition? The matter is not to see whether any method is acceptable. Rather we wanted to say how things could be arranged in a provocative way.

The teacher teaches but disruption is there. What should be done? In some cases teachers go beyond control and it leads to disturbance. Then why not organize teachers so that students will control themselves. On the other way if the students are more efficient than the teachers, then two things are expected to happen: either the class is going to be an interactive one as well as learning factor is concerned or the unpredictable reactions from the teachers.

But in some cases reversal technique proves successful as exemplified by Edward De Bono in the following:

- The duchess who was overweight consulted number of physicians who advocated her to control her appetite, but no result. Finally a physician recommended her to drink a glass of sweetened milk halfan-hour before all meals (Which of course reduced her appetite very much)

\section{IV.1.7 Be an idea Prone}

Think that you can do. Once this positive temperament sustains, ideas will pour in. You might have come across kids having funs with dolls and sometimes catch fire. The idea that fire burns comes after the accident occurs. Always think that ideas exist and open your mind to all possible solutions hovering around. In 1822, Danish physicist, Oersted, chanced to put a wire conducting an electric current close to a magnet and discovered an electric charge, thus discovered electricity. In 1889, Professors von Mering and Minowsaki while operating on a dog saw a swarm of flies being attracted to the dog's urine. After testing they found it contained sugar. This was the breakthrough towards a controlled drug for diabetes.

Get an idea and encircle it with all possible angles on which the topic could be discussed upon.

For example:

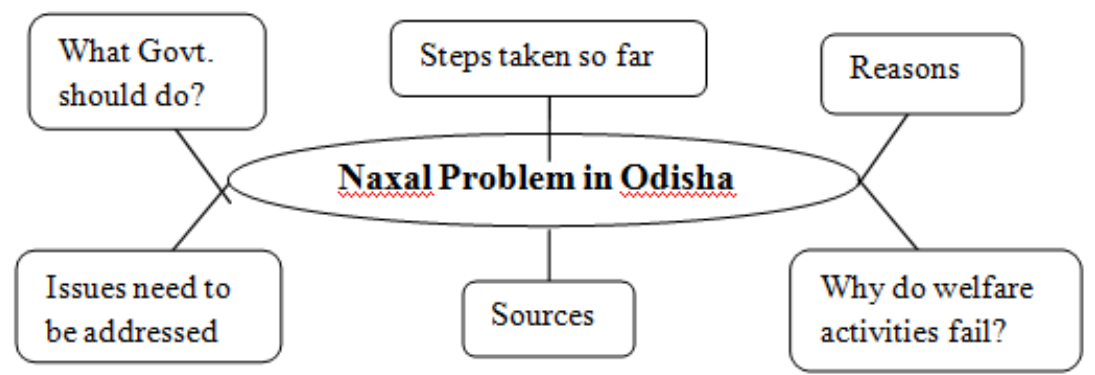

(Idea Mapping)

Fig. 02

\section{IV.1.8 Look for attractive ads}

Learn few creative tricks from the advertising experts. It is because there is no second chance at making a good impression. The average American is exposed to 5000 ads every day. In fact, (15) 'Wow Factor' works well here. Look at the following: (www.inspirationfeed.com, Apr-19, 2012)

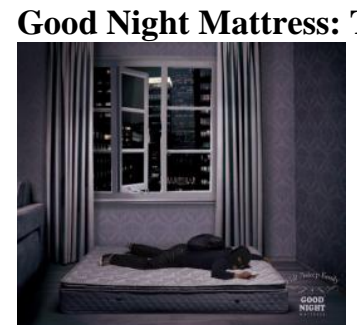

Fig.03

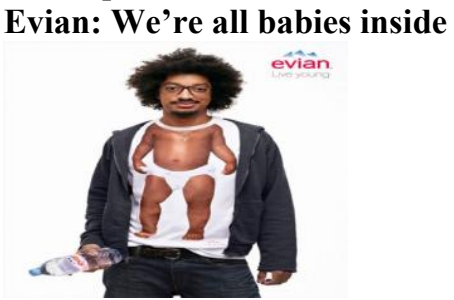

Fig.04

\section{Conclusion:}

Lateral thinking is a tool that has numerous advantages and practicing more will chisel our perceptions. We assume a lot and sometimes in a wrong way. In the day to day business these creative techniques may prove fruitful if organized in a proper sequence. Our limitations are the RISK factors. We escape and pretend frequently as we apprehend to face the unexpected consequences. Therefore, apply the technique without seeing what is actually not seen at the moment, because the charm of success that comes finally gives you a sense of euphoria. Remember that the easy way to overcome problems is to accept any one of the followings:

- Once should not get satisfied with whatever it is 
- Thinking always what differently can be done

- Accept failures as pillars of success.

- Make one your role model and follow his path

- Be assertive and develop pro activities.

- Never say "It's impossible" Say "It's difficult, but can be done"

- Find out many alternatives before you reach your final decision.

\section{Books}

\section{REFERENCES}

[1]. Jack Foster, HOW TO GET IDEAS: Have Fun (New Delhi: Viva Books Private Limited, 2008)

[2]. Edward de Bono, Lateral Thinking: Introduction (England: Penguin, 1990)

[3]. Edward de Bono, I am Right You are Wrong: Introduction: New Renaissance (England: Penguin, 1991)

[4]. Edward.de Bono, I am Right You are Wrong: Introduction: New Renaissance (England: Penguin, 1991)

\section{Interviews}

[5]. Gupta, Shekhar. Interview with de Bono. Walk the Talk with Dr.Edward de Bono and get one minute Primer on the Six Hats. NDTV 24x7's. New Delhi. 03 May. 2008

\section{Books}

[6]. Jack Foster, HOW TO GET IDEAS: Introdution: An easy to Follow Road Map (New Delhi: Viva Books Private Limited, 2008)

[7]. Paul Sloane, The Leader's Guide to Lateral Thinking Skills: The need for innovation: The challenge of change (United Kingdom: Kogan Page Limited, 2008

[8]. Paul Sloane, The Leader's Guide to Lateral Thinking Skills: The need for innovation: Lateral Thinking (United Kingdom: Kogan Page Limited, 2008)

[9]. Paul Sloane, The Leader's Guide to Lateral Thinking Skills: Making the vision real: Staying Focused (United Kingdom: Kogan Page Limited, 2008)

\section{Internet}

[10]. Refresher.com: H.Duell, Charls: policies...Keeping Us Thinking Inside the Box, 2004 _ 〈http://www.refresher.com/!lcbox.html>

Books

[11]. Jack Foster, HOW TO GET IDEAS: HAVE FUN. (New Delhi: Viva Books Private Limited, 2008)

[12]. Edward de Bono, Six Thinking Hats: Introduction: Argument versus parallel Thinking (Great Britain: Penguin, 2000)

[13]. Paul Sloane, The Leader's Guide to Lateral Thinking Skills: The need for innovation: Lateral Thinking (United Kingdom: Kogan Page Limited, 2008)

[14]. Edward de Bono, Lateral Thinking: The way the mind works: Humour and insight (England: Penguin, 1990)

\section{Internet}

[15]. Inspirationfeed.com: $\quad 50 \quad$ creative and Effective advertising examples. $\quad 2012 . \quad 19 \quad$ April 2012 < http://www.inspirationfeed.com/inspiration/advertising/inspirator > 